\title{
REPRESENTACIONES SOBRE LA UNIDAD SOCIAL Y LA IGUALDAD EN LA ARGENTINA CONTEMPORÁNEA. UN ANÁLISIS A PARTIR DE LOS ASALARIADOS DEL ÁREA METROPOLITANA DE BUENOS AIRES (AMBA)
}

\author{
Jorge CASTRO RUBEL ${ }^{1}$
}

\section{Resumen}

En el presente trabajo, presentamos los resultados de una investigación exploratoria acerca de las representaciones de trabajadores asalariados del Área Metropolitana de Buenos Aires sobre algunas dimensiones relativas a la unidad y la igualdad social en la Argentina contemporánea. En esta dirección, se analizan las representaciones sobre: la existencia de unidad o división entre los argentinos, la existencia de igualdad o desigualdad social en el país, las causas de las divisiones entre los argentinos, los grados de unidad/división observadas, el origen temporal de las divisiones, la unión de los argentinos en el futuro, las desigualdades que se observan, el porqué de las mismas, la responsabilidad que se le atribuye al Estado en cuanto a las desigualdades y cuáles serían estas.

El presente artículo se basa en el análisis de un conjunto de entrevistas realizadas a 15 trabajadores asalariados del Área Metropolitana de Buenos Aires (AMBA). Dichas entrevistas se realizaron entre mayo y junio de 2018. La selección de los trabajadores entrevistados se realizó mediante un muestreo en cadena.

Palabras clave: Representaciones, asalariados, unidad, igualdad, conflicto.

\begin{abstract}
In this article, we present the results of an exploratory investigation about the representations of salaried workers of Metropolitan Area of Buenos Aires on some dimensions related to the unit and the social equality in contemporary Argentina. In this direction, we analyze the representations about: the existence of unity or division among argentines, the existence of equality or social inequality in the country, the causes of
\end{abstract}

\footnotetext{
${ }^{1}$ Licenciado en Sociología (UBA), Doctor en Ciencias Sociales (UBA) e investigador del Instituto Gino Germani (UBA) y CONICET. Correo electrónico: jorsur77@hotmail.com
}

Fecha de recepción del artículo: Abril 2019

Fecha de evaluación: Mayo 2019 
divisions among argentines, the degrees of unity / division observed, the origin temporary division, the union of Argentines in the future, the inequalities that are observed, the reason for them, the responsibility that is attributed to the State in terms of inequalities and which would be these.

This article is based on the analysis of a set of interviews with 15 salaried workers of the Metropolitan Area of Buenos Aires (AMBA). These interviews were conducted between May and June 2018. The selection of the workers interviewed was carried out through a chain sampling.

Keywords: Representations, salaried workers, unity, equalities, conflict.

\section{Résumé}

Dans le présent travail, nous présentons les résultats d'une enquête exploratoire sur les représentations des travailleurs salariés de l'aire métropolitaine de Buenos Aires sur certaines dimensions liées à l'unité et à l'égalité sociale dans l'Argentine contemporaine. Dans ce sens, nous analysons les représentations concernant: l'existence d'unité ou de division entre les Argentins, l'existence d'égalité ou d'inégalité sociale dans le pays, les causes des divisions entre les Argentins, les degrés d'unité / division observés, l'origine division temporaire, l'union des Argentins dans le futur, les inégalités qui sont observées, leur raison, la responsabilité qui est attribuée à l'État en termes d'inégalités et quelles seraient celles-ci.

Cet article est basé sur l'analyse d'une série d'entretiens avec 15 salariés de la région métropolitaine de Buenos Aires (AMBA). Ces entretiens ont eu lieu entre mai et juin 2018. La sélection des travailleurs interrogés a été effectuée par échantillonnage en chaîne.

Mots-clés :Représentations, employés, unité, égalité, conflit.

\section{Introducción}

En el presente trabajo nos proponemos presentar algunos resultados de un trabajo de investigación orientado a avanzar en el estudio exploratorio sobre las representaciones de los trabajadores asalariados del AMBA acerca de la unión y la igualdad en la Argentina contemporánea. ${ }^{2}$

Este trabajo continúa una línea de investigación orientada a analizar las representaciones sobre estas temáticas y otras relativas a la conflictividad social en diferentes personificaciones sociales del AMBA, que ocupan distintos lugares en las relaciones

\footnotetext{
2 Por representaciones entendemos a las imágenes mentales que tienen los individuos acerca de un evento, una acción o una cosa. Estas representaciones constituyen una creencia en la medida en que son conservadas en la mente y son, asimismo, la base del significado que adquiere cada nuevo estímulo vinculado a esa acción, evento o cosa. Por otra parte, estas imágenes son construidas activamente por el sujeto, ya sea consciente o inconscientemente, a diferencia de las percepciones. Asimismo, pueden ser compartidas por medio de la comunicación, de ahí que las representaciones individuales pueden devenir representaciones sociales. Sin embargo, cabe destacar que no todas las representaciones individuales pueden convertirse en sociales, ya que no todas tienen las mismas posib ilidades de circulación. Por otra parte, las representaciones juegan un rol muy significativo en la vida humana, en tanto que las mismas condicionan el accionar de las personas (Raiter, 2010).
} 
sociales de producción (Tapia, Castro Rubel y Artese, 2017; Castro Rubel, Artese y Tapia, 2018; Artese, Castro Rubel y Tapia, 2017). ${ }^{3}$ Así, el presente trabajo continúa aproximaciones ya realizadas sobre pequeños empresarios, trabajadores de empresas recuperadas y sobre trabajadores asalariados. En esta ocasión, se optó por hacer nuevamente foco en las representaciones de una de las personificaciones sociales fundamentales en el proceso socio productivo capitalista: los trabajadores asalariados que no ejercen funciones de mando en el proceso de trabajo. De esta manera, no fueron entrevistados gerentes o encargados de establecimientos que, aunque se trata en muchos casos de asalariados, personifican en el proceso productivo funciones del capital y no puramente fuerza de trabajo. Se entrevistaron, en tal sentido, trabajadores asalariados pertenecientes a diversas ramas de actividad y con heterogéneas ocupaciones, con residencia en la Ciudad Autónoma de Buenos Aires (CABA) o en algún partido del denominado Gran Buenos Aires (GBA).

Ambas temáticas, la unidad y la igualdad, fueron ampliamente abordadas por las ciencias sociales desde sus orígenes, haciéndose énfasis en diversos elementos, ya sean de tipo objetivo como subjetivo (Nisbet, 1969). En esta línea, en los denominados "padres fundadores" de la sociología, la referencia a estas temáticas fue recurrente en sus obras (Marx, 2017; Weber, 2002; Durkheim, 1997). Este mismo camino fue seguido posteriormente por otros grandes autores de la sociología, como Norbert Elías, quien hizo de la cuestión de la cohesión social un elemento destacado de sus investigaciones y reflexiones (Elías, 1990).

En la actualidad, la unidad y la igualdad ${ }^{4}$ continúan siendo temas de amplio interés para las ciencias sociales, también con múltiples aproximaciones (Rosanvallon, 2015; Tilly, 2000; Therborn, 2015). ${ }^{5}$

En paralelo, en la Argentina contemporánea, el tratamiento de la cuestión de la unidad social ha desbordado los límites del mundo académico, instalándose en diversos espacios. Los medios de comunicación han sido, en este sentido, un ámbito en el que dicha temática ha cobrado amplio interés, bajo el término "la grieta" (Zunino y Russo, 2015). Si bien no todas las aproximaciones que emplean este término encierran la misma interpretación, una de ellas, quizás una de las más difundidas, plantea que los argentinos se encuentran recientemente "divididos", especialmente por razones políticas. Dicha división tiene, al mismo tiempo, una valoración negativa, entendiéndose la misma como un problema importante que atraviesa la Argentina. Por último, la división observada se atribuye a

\footnotetext{
${ }^{3}$ Este tipo de aproximación parte de las premisas del materialismo histórico, que establecen que las creencias se encuentran condicionadas por el lugar que se ocupa en las relaciones sociales de producción (Thompson, 2012).

${ }^{4} \mathrm{La}$ unidad y la igualdad son cuestiones diferentes. No obstante ello, pueden pensarse relacionadas. Siguiendo a Rosanvallon (2015), una relación entre ambas cuestiones puede ser la siguiente: "(La desigualdad) debe ser así percibida como un hecho social total. En efecto, no se limita a una cuestión de desigualdades de ingresos o de patrimonios. Hace vacilar las bases mismas de lo común. Dan testimonio de esto los diversos mecanismos de secesión, de separatismo y de aislamiento en guetos, en todas partes en marcha, que indujeron lo que propongo llamar desnacionalización de las democracias y que están en la base de su desgarramiento (...)" (Rosanvallon, 2015: 24). Una mirada similar es la de Therborn (2015): "La desigualdad de recursos abre un abismo entre las personas" (Therborn, 2015: 29).

${ }^{5}$ Sin embargo, sobre este punto, Rosanvallon (2015) sostenía un pensamiento pesimista: "Nunca se habló tanto de estas desigualdades y, al mismo tiempo, nunca se hizo tan poco para reducirlas" (Rosanvallon, 2015: 19).
} 
ciertas acciones emprendidas por los expresidentes Néstor Kirchner y Cristina Fernández durante sus gobiernos, que se desarrollaron entre 2003 y 2015 (Cotarelo, 2018). Por tal razón, siguiendo dicho diagnóstico, una vez fuera del gobierno Kirchner y Fernández, "la grieta" se iría cerrando progresivamente. Como se desprende de lo señalado, la posibilidad de interpretar las divisiones políticas en tanto resultado del orden socioproductivo dominante en la actualidad es dejada de lado. Las divisiones son presentadas, por el contrario, como una cuestión de tipo coyuntural. Al mismo tiempo, dicha explicación es empleada como herramienta para criticar ciertas experiencias de gobierno. No puede señalarse lo mismo con relación al tratamiento y difusión de la cuestión de la igualdad/desigualdad. Por el contrario, la aproximación a esta cuestión no parece concitar mayor interés, al menos en el ámbito de los grandes medios de comunicación masiva. Una hipótesis que manejamos para explicar la escasa referencia a la desigualdad en los grandes medios de comunicación sostiene que hablar de la misma puede abrir con cierta facilidad la posibilidad de cuestionar el orden social establecido, a partir del cual se da lugar a una distribución de perjuicios, pero también a una concentración de beneficios. En este sentido, en el plano económico, consideramos que es posible para los grandes medios de comunicación -y para los intereses que expresan- hacer referencia a uno de los resultados de la desigualdad económica, la pobreza, sin hablar del otro gran resultado de la desigualdad, la riqueza. ${ }^{6} \mathrm{Al}$ menos en los grandes medios de comunicación, la pobreza no es abordada en relación con la riqueza. De esta manera, la pobreza tiende a explicarse sin generar posibles críticas al sistema que la produce. ${ }^{7}$

Tal como señalamos anteriormente, el presente trabajo tiene como objetivo abordar exploratoriamente estas temáticas, la cohesión y la igualdad, desde una perspectiva particular: nos proponemos analizar las representaciones sobre la unión/desunión y la igualdad/desigualdad en la Argentina, según los trabajadores asalariados del AMBA. En esta dirección se realizaron un conjunto de entrevistas a asalariados de dicha área

\footnotetext{
${ }^{6}$ Con relación a este punto, el politólogo José Nun señaló lo siguiente en una entrevista reciente: "Hay un chiste que circulaba en Estados Unidos cuando estalló la burbuja financiera en 2008. Un empresario le decía a otro: "Si logramos que al saqueo se lo llame "crisis" estamos salvados". Creo que acá el chiste se podría reformular con un empresario diciéndole a otro: "Si logramos que a la desigualdad se la llame "pobreza”, estamos salvados" (Fernández Díaz, 2018).
}

\footnotetext{
7 Una forma habitual de explicar las desigualdades económicas desde los sectores económicamente beneficiados es mediante la responsabilización de los sectores perjudicados. Sobre este punto, hace más de un siglo y medio, Marx decía: "Esa acumulación originaria desempeña en la economía política aproximadamente el mismo papel que el pecado original en la teología. Adán mordió la manzana y de ahí provino el pecado para el género humano. Su origen se explica contándolo como una anécdota del pasado. En tiempos muy remotos hubo, de un lado, una minoría trabajadora, inteligente y sobre todo ahorrativa, y, del otro lado, haraganes ociosos que derrochaban cuanto tenían y aún más. La leyenda del pecado original teológico nos dice, sin embargo, cómo el hombre fue condenado a ganarse el pan con el sudor de su frente; pero la historia del pecado original económico nos revela por qué hay gente que no tiene ninguna necesidad de hacer esto. No importa. Así se explica que mientras los primeros acumulaban riquezas, los segundos no tuvieran finalmente nada que vender más que su pelleja. Y desde este pecado original arranca la pobreza de las grandes masas, que todavía hoy, a pesar de todo su trabajo, no tienen nada que vender más que a sí mismos, y la riqueza de unos pocos, que aumenta continuamente, aunque hace mucho que dejaron de trabajar". (Marx, 1976: 197-198).
} 
metropolitana. Se avanzó con la realización de entrevistas ya que se estimó que este tipo de instrumento de recolección de información era el más adecuado para cumplir con los objetivos de la investigación. Como marcamos anteriormente, el estudio es de carácter exploratorio y se siguió un criterio no probabilístico (muestreo en cadena) para la selección de los casos a entrevistar. Las entrevistas se realizaron entre mayo y junio de 2018 y se entrevistó a un total de 15 trabajadores asalariados, de los cuales 7 eran varones y 8 , mujeres. Por todo esto, se señala que los resultados no son generalizables. La edad promedio de los entrevistados era de 33,2 años. Todos ellos eran trabajadores ocupados al momento de realizarse las entrevistas. Asimismo, puede señalarse que tenían diversas ocupaciones. En este sentido, se entrevistó a una médica, una enfermera, un técnico en ascensores, dos operarios fabriles, un empleado de control de calidad, una ingeniera en alimentos, una contadora, un empleado gastronómico, un vendedor y cinco empleados administrativos.

Las preguntas que se buscarán responder en el trabajo son las siguientes: ¿Consideraban los asalariados entrevistados que los argentinos se encontraban unidos o divididos? ¿Qué tan divididos se encontraban los mismos? ¿Qué motivos explicaban -en su perspectivalas divisiones que observaban? ¿Desde cuándo estaban divididos? ¿Creían que en el futuro los argentinos se iban a unir? ¿Qué creían que hacía falta en tal dirección? ¿Creían que existían desigualdades en la Argentina contemporánea? ¿Cuáles detectaban? ¿Por qué existían las mismas? ¿Pensaban nuestros entrevistados que el Estado tenía alguna responsabilidad en las desigualdades que se observaban? ¿Cuál o cuáles serían esas responsabilidades?

A partir de aquí, el presente trabajo se ordena del siguiente modo: En primer lugar, se presentan los resultados de los estudios realizados sobre las representaciones acerca de diversas dimensiones de las divisiones sociales en la Argentina; a continuación, se exponen los resultados de las indagaciones sobre las representaciones acerca de algunas dimensiones relativas a la desigualdad social en el país y, por último, se esbozan algunas conclusiones sobre las representaciones relativas a ambas cuestiones.

\section{La división social en la Argentina actual}

Tal como señalamos en la introducción al presente trabajo, en la primera parte se analizan dimensiones relativas a la cuestión de las divisiones sociales. ${ }^{8}$

En tal sentido, la primera cuestión que nos interesa abordar acerca de las divisiones sociales es si los entrevistados consideraban que los argentinos se encontraban en términos generales unidos o divididos al momento de realizarse la entrevista. En esta dirección, les preguntamos: "En su opinión, ¿los argentinos nos encontramos unidos o divididos?". 9

\footnotetext{
${ }^{8}$ Llegados a este punto, y antes de continuar, creemos conveniente realizar dos señalamientos de orden teórico sobre este tema. En primer lugar, afirmamos, siguiendo los señalamientos de la teoría de la lucha de clases, fundada por Marx y Engels, que los argentinos, del mismo modo que en todas las sociedades capitalistas contemporáneas, se encuentran divididos en clases sociales, cada una de ellas con intereses materiales propios y contradictorios. Por lo tanto, más allá de uniones coyunturales o en virtud de ciertos temas de menor importancia, creemos que lo distintivo entre los argentinos es la división, debido a la existencia de clases sociales. En segundo lugar, que dicha división no tiene un origen reciente sino lejano. ${ }^{9}$ Lo que se buscaba con la pregunta era conocer las representaciones sobre este punto en tanto un balance general que pretendíamos que nuestros entrevistados realizaran.
} 
De los 15 trabajadores entrevistados, casi la totalidad de estos sostuvieron que los argentinos se encontraban "divididos". En tan sólo un caso se planteó la idea de que los argentinos se encontraban "unidos". Sin embargo, esta opinión contenía una salvedad al respecto. En este caso, se señalaba: "el común de la gente está unida, tiene los mismos objetivos". No obstante, ésta entrevistada reconoció que existía una división política en el país, la cual minimizó al momento de hacer un balance. Con todo, lo ampliamente dominante (14 casos) entre los asalariados entrevistados era la idea de que los argentinos se encontraban desunidos en términos generales.

Por otra parte, se observó que un grupo de quienes entendían que los argentinos se encontraban divididos, poco más de la mitad de éstos (nueve casos), remarcaron que dicha división era fuerte. ${ }^{10}$ En estos casos, para dar cuenta de esta representación se emplearon definiciones como las siguientes: "hay mucha desunión", "estamos muy divididos", "estamos bastante divididos", "está muy marcada la división”, "es tajante” y "nos veo muy claramente divididos", entre otras.

Esta representación ampliamente mayoritaria acerca de que los argentinos se encontraban "divididos" era desde nuestro punto de vista coherente con los señalamientos teóricos realizados más arriba. Asimismo, resultaba coherente también con la larga historia de conflictos que tuvieron lugar en el territorio argentino desde la independencia del país, a comienzos del siglo XIX (Romero, 2013). ${ }^{11}$ Incluso, también podemos agregar que era también afín al discurso previamente referido de "la grieta". No obstante ello, señalar esto no significa sostener aquí -aunque tampoco descartar- alguna hipótesis acerca de las razones que pueden explicar las representaciones referidas.

Pasemos ahora a analizar una segunda cuestión: ¿cuáles eran, en la perspectiva de nuestros entrevistados, las razones por las que los argentinos se encontraban divididos? ${ }^{12}$ ¿Qué explicación o explicaciones encontraban acerca de la realidad que describían? Del total de respuestas obtenidas, hemos desentrañado cinco diferentes tipos de argumentos que buscaban explicar las divisiones que se habían señalado. Antes de dar cuenta de las explicaciones brindadas, es conveniente señalar que fue usual que nuestros entrevistados explicitaran más de un argumento para tratar de explicar las divisiones previamente referidas. En tal sentido, registramos un número mayor de argumentos que de entrevistados.

Una primera explicación que encontramos acerca de las divisiones sociales y, asimismo, la más recurrentemente mencionada (seis ocasiones), sostenía que las mismas tenían origen en la existencia de intereses políticos. En esta línea, coexistían -en su interior- dos argumentos que colocaban el acento en diferentes cuestiones, pero que coincidían en

\footnotetext{
${ }^{10}$ Esto no significa, sin embargo, sostener que el resto de los entrevistados que señaló que los argentinos se encontraban divididos interpretaban que la división era leve. No hubo de nuestra parte una pregunta directa sobre qué tan importante era la división; en tal sentido sólo se informa que un grupo decidió remarcar espontáneamente que se trataba de una división fuerte.

${ }^{11}$ Sólo a título ilustrativo podemos mencionar las divisiones y enfrentamientos sostenidos entre "Unitarios" y "Federales" en el siglo XIX, la persecución y represión estatal del movimiento anarquista a comienzos del siglo XX, las luchas entre "Peronistas" y "Antiperonistas", a mediados del siglo XX, las luchas entre los gobiernos del Estado y el movimiento de la nueva izquierda, en los 60 y 70 y la posterior represión a estos movimientos políticos de parte del Estado, entre otros.

${ }^{12}$ Con respecto a esta cuestión, se le preguntó a cada uno de los trabajadores entrevistados lo siguiente: “¿Cuál o cuáles serían las razones por las que estamos divididos?”.
} 
interpretar a las divisiones sociales como resultado de la existencia de intereses de orden político. Por un lado, uno de los argumentos, que registramos en un solo caso, sostenía que dicha división se daba por la existencia de posiciones políticas contradictorias presentes en diferentes sectores de la sociedad, y que estas posiciones tenían origen en intereses opuestos. De esta manera, a partir de la existencia de intereses políticos contradictorios la sociedad se dividía. Por otro lado, desde una lectura heterónoma de la realidad social, un segundo argumento sostenía que la sociedad había sido dividida políticamente a partir de la acción de determinadas personificaciones sociales que se presentaban como externas al mismo entramado social. La sociedad argentina era presentada -en esta mirada- como un sujeto pasivo de un accionar externo. A diferencia del argumento anterior, en este caso, ciertas personificaciones llevaban adelante determinadas acciones -motivada por algún tipo de interés- que originaban que la sociedad se dividiera. En este esquema, se les otorgaba a los medios de comunicación un papel relevante en la generación de las divisiones.

Veamos los ejemplos. El primero de ellos ejemplifica el primer tipo de argumento, mientras el segundo y el tercero reflejan el segundo tipo de argumentación:

\begin{abstract}
"Vos veías que todo el reclamo era porque no voy a llegar a cobrar mi jubilación, te decian unos, otros que peleaban por el tema del impuesto a las ganancias y esa era la división, unos que reclamaban por eso y que no me voy a jubilar, que querían un cambio, tuvieron el cambio y estamos cada vez más atrás”. (Juan, 32 años, operario en fábrica de mamparas).
\end{abstract}

“(...) y bueno empezó toda una campaña también de parte del gobierno contra el gobierno anterior, también de desprestigio, una competencia entre las opiniones de la gente y me parece que también hubo toda una influencia de parte del periodismo también sobre la gente para dividirnos más. (...) "No, en realidad no es que tengo asi la certeza de que haya algo... pero me parece que sí hay una influencia a nivel, no sé, de poderes económicos que tenían el interés de que este gobierno que está actualmente asumiera y, bueno, hubo como toda una movida... a nivel de los medios como para influir sobre la opinión pública"'” (María, 43 años, médica).

"Yo creo que es una gran estrategia, no sé si enaltecer tanto la figura de Durán Barba, pero es una estrategia claramente mediática, en el sentido de la frase "divide y triunfarás", en ese sentido para mí está vinculado a esta estrategia en la cual ennegrecer tanto la figura de Cristina". (Rubén, 29 años, vendedor).

Una segunda forma de explicar las divisiones refería a la existencia de visiones del mundo diferentes (cinco ocasiones). En este esquema, había diferentes representaciones acerca del mundo, diferentes formas de interpretar la realidad en distintos aspectos, lo que impedía la unión entre los integrantes de una población determinada.

Aquí, la división se explicaba solamente por una cuestión de orden subjetivo y no se ponía en relación con algún factor de orden objetivo. A diferencia de una de las perspectivas anteriores, en esta explicación las divisiones no tenían origen en un determinado actor social exógeno que lograba generar la división, sino que se trataba de puntos de vista contradictorios que se gestaban en la dinámica social sin hacerse hincapié en alguna personificación particular. Ejemplos de esta perspectiva serían los siguientes: 


\begin{abstract}
"Porque hay diferentes opiniones con respecto... la vivencia de ahora más que nada. Antes era diferente, antes era otra cosa. Pero ahora es diferente porque no pensamos iguales. Más que nada somos un poco más egoístas, pensamos en nosotros. Por eso pienso que generalmente ahora más que nada estamos un poco... somos divididos no pensamos iguales". (Celia, 59 años, enfermera).

"Esos grupos tienen una visión particular de la realidad cada uno, o etiquetan en base a una premisa (...). Porque tienen justamente visiones distintas. El matrimonio homosexual, la ley del aborto". (Julio, 25 años, empleado administrativo).

"La cosmovisión que tenemos del mundo, hay una marcha y yo la celebro y ellos se quejan, y eso divide". (...) "Para mí es en todo. Estas personas no es que sean partidarios de algo. Mis compañeros, al hablar de la vida o alguna situación, ellos están en la vereda de en frente”. (Paula, 29 años, empleada administrativa).
\end{abstract}

Otra forma de explicar las divisiones ponía atención en el "estilo de vida" (tres ocasiones). Aquí, hemos agrupado tres tipos de explicaciones de las divisiones que ponían el énfasis en diferentes elementos propios del tipo de vida actual. En estas explicaciones, las divisiones no se darían por algún tipo de enfrentamiento sino, más bien, por una falta de "agregación" resultante del estilo de vida actual:

"Me pasa que ahora estoy buscando laburo y me encantaría seguir haciendo eso y venir a la facultad, pero inevitablemente tengo que meter otro laburo, inevitablemente las condiciones de vida llevan a una individualización más grande. Estás metido en tener que progresar y estudiar y no te podés ocupar de otras cosas." (Facundo, 21 años, empleado gastronómico).

"Yo creo que ha cambiado mucho también, lo que nos hace cambiar, la poca comunicación entre nosotros, porque el tema de los celulares, las computadoras, en ese auge fue el cambio más que nada. Porque hoy por hoy los chicos si necesitan algo lo primero que hacen es la computadora". (Celia, 59 años, enfermera).

"Siento que todas las ciudades capitales del mundo o que son metropolitas o que son cosmopolitas de una forma u otra tienen mucha más conexión entre sí que dentro de otras ciudades de su mismo país... por ejemplo, yo estoy totalmente convencida de que yo tengo mucho más que ver con un joven promedio de Madrid o de Roma o de Estados Unidos o de Japón que con una persona de 27 años del impenetrable del Chaco. Siento que con otras ciudades cosmopolitas tenemos los mismos idolos, los mismos lenguajes, usamos pantalones de jeen, cosas que están intrínsecas a las personas y que están meramente relacionadas con ser o no una ciudad globalizada". (Giuliana, 28 años, empleada administrativa).

Una cuarta forma de explicar las divisiones sociales hacía foco en cuestiones de tipo económico (cuatro ocasiones). En este tipo de explicaciones había una cuestión central que atravesaba a todas ellas: las divisiones eran entendidas como la resultante de la existencia de intereses económicos contrapuestos entre empleados y empleadores o entre quienes tenían mayores recursos económicos y quienes tenían menos. La división se 
originaba, en suma, por la existencia de intereses materiales enfrentados que impedían la unidad.

A continuación, se presentan los siguientes ejemplos:

"La división que hay entre un patrón y un empleado. Ahí hay una división (...) Te reclaman una hora, "soy todos los días esclavo tuyo". (Juan, 32 años, operario en fábrica de mamparas).

"No soy un historiador, ni mucho menos, pero lo que noto que la Argentina siempre fue muy desigual en su crecimiento. Donde acá llegaron los inmigrantes y 5 familias se adueñaron de las tierras y cuando se las otorgaban a la gente esas tierras se las alquilaban en consignación y trabajaban para ellos. Cosa que en otros países no pasaba. En otros países, en general se les asignaba un lugar que era de ellos, entonces generó algo más nacionalista de conjunto. En la Argentina como que estuvo enfrentado, siempre hubo una masa popular laburadora ... que laburaba para otro que lo explotaba, entonces eso me parece que generó conflicto entre clases y desde el nacimiento de la Argentina. Pienso que tiene que ver un poco con eso". (Gustavo, 42 años, control de calidad).

"Y en el sentido de que hay gente que la pasa bien económicamente y gente que la pasa mal. Todo lo que salió a anunciar el gobierno es para que los que se quieren llevar dólares del país se los lleven tranquilamente y para el otro lado es ajuste fiscal, aumentar tarifas... Entonces la división es también económica, no solo política". (Sergio, 37 años, operario metalúrgico).

Una última forma de explicación de las divisiones ponía el foco en lo que podríamos denominar como la "esencia argentina" (cuatro ocasiones). En este tipo de argumentos, no había un intento por explicar socialmente las divisiones. Por el contrario, las mismas se debían a un cierto modo de "ser argentino", una "esencia", sobre la cual no se precisaba un origen. Por el contrario, se trataría de un rasgo que "siempre" estuvo entre los argentinos. En esta línea, los argentinos estarían divididos porque "son así", según esta explicación.

Veamos los ejemplos:

"No sé, son muchos factores, muchas cosas, distintos factores, formas de pensar diferentes. Aparte qué se yo, hoy en día uno piensa diferente que el otro o el otro reacciona agresivo... o no sé, hay un montón de factores... (...) Creo que el argentino en sí es asi ya, la esencia de pensar diferente que el otro, de pelear por sus ideas, ya somos así. Siempre fue así." (Elías, 26 años, técnico en ascensores).

"Somos argentinos y los argentinos somos bastante radicales en todo, digamos... nos gusta... no nos gusta... queremos, no nos queremos... lo amamos ... lo odiamos... en general el argentino tiene poco intermedio... los hay, pero en general somos bastante obcecados y obsecuentes con esa postura por el orgullo que tenemos." (Gustavo, 42 años, control de calidad).

"No sé si es de Argentina nada más, pero a la gente le gusta discutir, le gusta pelearse, le gusta estar buscando el contrapunto, siento eso. Hay temas que por ahi 
nos unen más, temas más banales, por ejemplo, temas más de futbol, más en esta época, y después cuando hay que poner un poco más de convicción no nos ponemos tan de acuerdo. Temas como el aborto, política, educación. Creo que la gente busca la discusión, lo que me preocupa es que se busca muchas veces la discusión por la discusión misma y no debatir ideas o tratar de entender al otro". (Natalia, 33 años, ingeniera en alimentos).

Como puede observarse en los ejemplos presentados, las razones que explicaban las divisiones señaladas eran heterogéneas. No obstante, es posible desentrañar un puñado de argumentos a partir de realizar un ejercicio de abstracción sobre la totalidad de las respuestas recolectadas. De esta manera, hemos clasificado cinco tipos de explicaciones diferentes. Como puede verse, la elaboración de las explicaciones no es pareja en todos los casos. Se registraron respuestas más complejas junto con otras que lo eran menos. No obstante, con mayor elaboración o con menos, según el caso, los entrevistados tendieron en su mayoría a explicar social e históricamente las divisiones en diferentes campos de la acción social. En oposición, fueron minoritarias las respuestas que buscaron explicar las divisiones a partir de una determinada forma no mutable de "ser argentino", que puede interpretarse como cierta esencia argentina.

\section{La dimensión temporal de la división}

Otra dimensión de las representaciones acerca de las divisiones sociales que nos interesa analizar es la relativa a la cuestión temporal. Hay sobre este punto dos cuestiones que abordamos: a) desde cuándo se consideraba que existían las divisiones ${ }^{13}$ y b) si era posible que se diera una unión entre los argentinos en el futuro. ${ }^{14}$

Tal como señalamos más arriba, en cierto discurso periodístico y político de gran difusión, las divisiones son interpretadas como recientes. En dicha perspectiva, la "grieta" se generó en los años de los gobiernos de Néstor Kirchner y Cristina Fernández, a partir de las acciones de ambos dirigentes políticos. Es decir, entre 2003 y 2015. En tal sentido, de ello se desprende que las divisiones se generaron sobre una aparente unidad social previa, que los gobiernos kirchneristas vinieron a romper. Más arriba, también señalamos la incongruencia de dicha interpretación de la realidad, tanto desde un punto de vista teórico como desde los hechos. Por otra parte, en dicho tipo de discurso se planteaba que una vez terminado el gobierno kirchnerista la reconstitución de la unidad sería una posibilidad cierta.

Ahora bien, ¿desde cuándo se encuentran divididos los argentinos en la mirada de los asalariados entrevistados?

Con relación a este tema, se puede clasificar las respuestas de nuestros entrevistados en dos grupos diferentes. Por un lado, las que sostenían que las divisiones sociales en la Argentina tenían un origen lejano en el tiempo y, por el otro, las que afirmaban que las mismas eran temporalmente recientes en cuanto a su inicio. Existía en este sentido respuestas que contemplaban el largo plazo para situar el origen de las divisiones y respuestas que tomaban solamente el corto o mediano plazo para ello. En estos últimos

\footnotetext{
${ }^{13}$ La pregunta formulada fue la siguiente: "Desde cuándo estamos divididos?”.

${ }^{14}$ La pregunta formulada fue: “¿Usted cree que es posible que en el futuro es posible que los argentinos estemos más unidos que en la actualidad? ¿Qué hace falta para que ello suceda?”.
} 
casos, es posible que se desconocieran los históricos enfrentamientos sucedidos en la Argentina. En esta línea, hay que tener en cuenta que para conocer hechos que transciendan al sujeto en términos cronológicos o de experiencias de la propia vida es necesario contar con un conocimiento indirecto que muchas veces no fue adquirido por diversas razones. Sin pensar que pueda ser la única causa, entre ellas, nos interesa destacar el esfuerzo que se realiza cotidianamente desde posiciones privilegiadas en la estructura social para que no se logre problematizar en profundidad las diferentes aristas del orden social, entre ellos las divisiones y el conflicto social, elementos propios del orden social capitalista. ${ }^{15}$ De esta manera, es posible encontrar entrevistados que desconozcan hechos de lucha de su propia clase, hayan tenido lugar estos en un lejano pasado como en un pasado algo más reciente.

Desde un punto de vista cuantitativo, las referencias que entendían que las divisiones tenían su origen en el largo plazo eran mayoría (once casos), sobre las que ubicaban en un momento reciente el origen de las mismas (siete casos). ${ }^{16}$

Veamos algunos ejemplos acerca de cómo se problematizaba la cuestión del origen de las divisiones sociales:

"Hoy los medios nos quieren hacer creer que es algo del momento, me parece que es algo histórico de la Argentina la división". (...) "Desde hace 200 años que se generó Argentina ...pero por la misma forma de cómo Argentina se genera. Yo digo desde antes de la generación de Argentina como Argentina. Creo que en la generación de Argentina hubo próceres como Belgrano, Mariano Moreno, que tenían otra visión de país... y eran bastante más... una Argentina que yo hubiera pretendido... pero bueno... ya estaba generado... desde antes de 200 años... con la invasión de alguna manera, española, inglesa ... están esas divisiones". (Gustavo, 42 años, control de calidad).

"A ver, siempre existió la cosa... diferentes no bandos, no serían bandos, en términos políticos no conozco, pero sí yo veo que estaban los radicales, los peronistas, si bien habia obviamente como ideas diferentes yo creo que el kirchnerismo hizo que haya una grieta. Realmente la gente empezó a confrontar bastante, ¿no?” (Noelia, 32 años, contadora).

"Yo creo que hace unos 15 años más o menos que ahi se empezó el tema para mi punto de vista. Porque antes, no" (Celia, 59 años, enfermera).

\footnotetext{
${ }^{15}$ En esta línea, con relación a la organización obrera y al campo de la lucha, es pertinente recordar las palabras de Rodolfo Walsh (2018), en referencia al "Cordobazo": "Nuestras clases dominantes han procurado siempre que los trabajadores no tengan historia, no tengan doctrina, no tengan héroes ni mártires. Cada lucha debe empezar de nuevo, separada de las luchas anteriores. La experiencia colectiva se pierde, las lecciones se olvidan" (Walsh, 2018).

${ }^{16}$ Cabe aquí destacar que las referencias fueron cuantitativamente más que los entrevistados, en la medida en que hubo entrevistados que refirieron temporalidades para las diferentes divisiones que observaban. Incluso, en algunos casos, dichas temporalidades señaladas eran diferentes. Por ejemplo, para las divisiones de tipo económico se señalaba que existían "desde siempre", mientras que las divisiones políticas tenían un origen temporalmente próximo.
} 
Pasemos ahora a analizar la segunda cuestión relativa a la temporalidad. ¿Se vislumbraba un futuro en unidad para los argentinos? ¿Se pensaba que era posible en el futuro superar las divisiones? ¿Qué se creía que hacía falta para que ello sucediera?

Nuevamente aquí nos encontramos con dos grupos diferentes de respuestas de los trabajadores asalariados: por un lado, las que vislumbraban un futuro en unidad, por el otro, las que no lo podían intuir en esos términos. Cuantitativamente, las respuestas "pesimistas", es decir aquellas que consideraban que no veían unidos a los argentinos en el futuro, eran ampliamente más que las "optimistas" (once respuestas contra cuatro, respectivamente).

Ahora bien, más allá de que vislumbraran un futuro de unidad o no, ¿qué creían los trabajadores entrevistados que tenía que suceder para que los argentinos se unieran?

De las respuestas recolectadas, se observa que nuestros entrevistados señalaron cuatro tipos de escenarios diferentes que podrían generar la unidad entre los argentinos: a) cuando tuviera lugar una gran crisis económica y política, b) cuando pasara cierta cantidad de tiempo, c) cuando existiera tolerancia ante las opiniones diferentes y d) cuando se diera un cambio en el personal político que gobierna el país.

Veamos ejemplos de las respuestas mencionadas:

"Y yo creo que la unión va a ser cuando... no sé, como pasó en el 2001. Hubo una unión que hicieron que se vaya el que estaba en el poder. Creo que llega un momento que ya van a sacar tanto que "bueno, ya, listo, ya si no me aumentan, vamos a reclamar juntos porque vamos a ser esclavos". (Juan, 32 años, operario en fábrica de mamparas).

"Yo creo que sí, si cambia la política. A lo largo de los años siempre son los mismos. Yo creo que en la política pasa eso, no puede venir gente nueva, con nuevas ideas y llegar a algún lugar para cambiar las cosas. (...) Los que mueven siempre son los mismos y hasta que eso no cambie no sé si se va a poder ver algún cambio así como estructural." (Noelia, 32 años, contadora).

"Totalmente. Estoy seguro que con el tiempo el fenómeno de unión se va a producir con el tiempo". (Julio, 25 años, empleado administrativo).

"Si tuviéramos la capacidad de escuchar más al otro, de ponernos en el lugar del otro, de tratar de entender. Podríamos tener más una visión común y tirar todos para el mismo lado como grupo y no tanto como individuo". (Natalia, 33 años, ingeniera en alimentos).

Como puede observarse, las "recetas" eran variadas. Sin embargo, todas tenían en común que, en ningún caso, los entrevistados mencionaron la necesidad de que se llevaran adelante cambios sistémicos para que se generara la "unidad de los argentinos". Este tipo de cambio radical estaba ausente en su repertorio de "formulas". Si se necesitaban cambios, estos eran cambios "dentro del sistema" (Coser, 1961). La unidad podría surgir a partir de cambios de una escala mucho menor, como podría ser que una nueva generación de políticos gobernara el país. 


\title{
La desigualdad social
}

Una segunda cuestión que queremos tratar de manera exploratoria en este trabajo, tal como señalamos en el inicio, es la relativa a las representaciones acerca de la igualdad y la desigualdad social entre las personas, entendiéndose a esta última en diversos planos de la vida social. En tal dirección, forman parte de nuestro interés aquí indagar sobre las representaciones relativas a las desigualdades de género, económicas, educativas, de poder, etcétera.

En relación con las representaciones acerca de esta cuestión, observamos que nuestros entrevistados entendían de manera unánime que en la Argentina existían desigualdades sociales entre los diversos habitantes del país. ${ }^{17}$ Sobre este punto, no registramos posiciones que señalaran que no existieran desigualdades en la Argentina actual.

Ahora bien, ¿cuáles eran las desigualdades percibidas por la población de asalariados entrevistada?

Las desigualdades observadas y referidas fueron relativamente diversas. Por caso, registramos representaciones que describen ocho diferentes tipos de desigualdades. En la perspectiva de los asalariados entrevistados existían en la Argentina contemporánea desigualdades de los siguientes tipos: económico, de género, educativo, racial, de orientación sexual, de acceso a la salud, cultural y de poder. Por mucho, la existencia de desigualdades de tipo económico fue la más mencionada (14 respuestas). En segundo lugar, aunque de lejos, esta fue seguida por la referencia a la desigualdad de género (cinco casos). ${ }^{18} \mathrm{~A}$ continuación se mencionaron las desigualdades por cuestiones raciales (tres casos). Luego, las desigualdades en lo que respecta a la educación (dos menciones). Con una misma cantidad de referencias se ubicaron las desigualdades de poder, cultural, acceso a la salud y orientación sexual, todas ellas mencionadas en una sola oportunidad. Por otra parte, cabe destacar que en más de una ocasión los entrevistados señalaron más de un tipo de desigualdad.

Veamos algunos ejemplos de las desigualdades observadas y señaladas en las entrevistas:

\begin{abstract}
"Socialmente, como podés ver a alguien que baja de un auto importado, como podés ver a alguien durmiendo en la calle. En ese sentido no hay igualdad. No sé, creo que... de género, ahora está un poco más igualado. La mujer tiene más derecho a otras cosas. Hay cosas en que hay igualdad y cosas que no". (Elías, 26 años, técnico en ascensores).
\end{abstract}

“O sea, bueno, desde la parte de educación, el acceso a la educación... Yo creo que hay división de clases. Los que pueden acceder a algo más alto, la clase trabajadora y la clase pobre. En el medio como que fue cambiando, pero no, y yo creo que no todos accedemos a lo mismo. La educación es una de las cosas donde más se ven". (Noelia, 32 años, contadora).

\footnotetext{
${ }^{17}$ La pregunta que realizamos fue la siguiente: "Por otra parte, ¿cree que en la Argentina de hoy somos todos iguales? Si no es así, ¿qué diferencias ve usted?”.

${ }^{18}$ Corresponde señalar que las menciones de las desigualdades de género se produjeron en el marco de un fuerte movimiento social de igualación de derechos entre varones y mujeres, que se llevaba adelante en la Argentina al momento de realizar las entrevistas.
} 


\begin{abstract}
"Y, yo no camino por la calle y me meten presa porque soy morocha o lo que sea... y hay mucha gente que sí..., pasa todo el tiempo. O yo puedo dormir en la calle quizás y nadie me va a decir nada y hay gente que no. En Córdoba pasa mucho que los pibes más pobres por portación de cara los agarran y los meten presos y los cagan a palos. A mi nunca me pasaría algo así. Y se hacen marchas y todo al respecto. (...) Las mujeres ganamos menos que los hombres, eso es desigualdad". (Camila, 29 años, empleada administrativa en empresa realizadora de comerciales).

"La gente más humilde es como que no está considerada. Mismo pasa en un sanatorio, que se yo, tenés el paciente que tiene la obra social, una prepaga más cara y tiene más privilegios a la hora de acceder a la salud también. El tipo que va, que tiene PAMI, que no tiene obra social, va al hospital público... (...) Una diferencia social importante. A igualdad de enfermedad, de gravedad, no tienen el mismo acceso a la salud”. (María, 43 años, médica).
\end{abstract}

Como puede observarse en estos ejemplos, las desigualdades consideradas contemplan varios temas. Asimismo, dichas desigualdades tenían en la perspectiva de los asalariados consecuencias diferentes. Es decir, daban lugar a diferentes escenarios vitales. Esto puede observarse, por ejemplo, en el caso de las desigualdades económicas. En los ejemplos que presentamos más arriba, puede verse que en la perspectiva de los asalariados entrevistados la desigualdad económica daba lugar a un diferente acceso a la salud o a un tratamiento diferencial de parte de las fuerzas represivas del Estado. ${ }^{19}$

Vayamos, ahora, a analizar qué explicaciones encontraban a las desigualdades que lograban observar y destacar. ${ }^{20}$

Las explicaciones que dieron a dicha cuestión fueron también diversas, del mismo modo en que lo hicieron con respecto a las divisiones sociales. Varios factores fueron planteados como causales de las desigualdades. Registramos seis argumentos diferentes para explicar las diversas desigualdades informadas anteriormente.

Aquí también puede observarse que explicar los hechos sociales es una tarea ardua y en ningún caso inmediatamente accesible. Observamos en tal sentido respuestas con diferentes grados de elaboración. Por otra parte, cabe señalar que solamente ocho entrevistados respondieron a la pregunta acerca de por qué existían desigualdades en la Argentina.

Un primer tipo de explicación que recogimos atribuía las desigualdades señaladas al modo de producción reinante en la Argentina, el capitalismo. En este esquema interpretativo, existían desigualdades en la Argentina, y estas se debían al orden socioproductivo dominante en el país, el capitalismo.

En este tipo de explicación, el énfasis estaba -entonces- colocado en el nivel de sistema y no en una cuestión de tipo coyuntural.

Con relación a este tipo de argumentación, es importante tener en cuenta que la referencia al "sistema capitalista" como explicación de las desigualdades puede no suponer en todos

\footnotetext{
19 Estas miradas son coincidentes con la interpretación que hacía Therborn (2015) sobre las diferentes experiencias de vida a que dan lugar la posesión diferencial de recursos materiales. Para este autor, la desigualdad "reduce nuestras capacidades de funcionar como seres humanos, nuestra salud, nuestro amor propio, nuestro sentido de la identidad, así como nuestros recursos para actuar y participar en este mundo" (Therborn, 2015: 9).

${ }^{20}$ Con este objetivo, preguntamos: "Y en su opinión, ¿por qué existen esas diferencias?”.
} 
los casos una compresión rigurosa acerca del modo de producción capitalista de parte de nuestros entrevistados. ${ }^{21} \mathrm{Al}$ leer las respuestas recolectadas, puede intuirse que es probable -aunque por el tipo de aproximación no lo sabemos con certeza- que la referencia al sistema proviene de un conocimiento dispar acerca de los principales elementos que componen dicho sistema económico-social.

Recolectamos un total de cuatro referencias de este tipo.

Veamos algunos ejemplos:

"A que asi funciona el sistema en su conjunto, cómo funciona el capitalismo, que es lisa y llanamente eso: la explotación de una clase por otra". (Sergio, 37 años, operario metalúrgico).

"Supongo que el sistema capitalista no podría funcionar si no hay alguien rico que a su vez es rico porque hay otro que es pobre. Es como la concepción del sistema económico en el que estamos inmersos. Y eso es algo que se mantiene a lo largo de los años y que es hereditario prácticamente. Estoy bastante segura que el ascenso socio-cultural o socio-económico es realmente difícil por todas estas trabas que mencioné antes". (Giuliana, 28 años, empleada administrativa).

Un segundo tipo de explicación de las desigualdades refiere a la existencia del "patriarcado". Es decir, a la existencia de relaciones sociales estructuradas que establecen un tratamiento diferencial a varones y mujeres, ubicándo a estas últimas en un nivel de inferioridad respecto de los hombres. Recogimos dos referencias de este tipo.

A continuación, presentamos los ejemplos:

“Por qué existen esas diferencias?... porque la sociedad está planteada me parece ... me sale dar ejemplos. Las mujeres no tenemos muchos derechos porque vivimos en una sociedad patriarcal básicamente". (Camila, 29 años, empleada administrativa en empresa realizadora de comerciales).

"El capitalismo y el patriarcado ejerce una presión sobre varones y mujeres, no sé qué habrá venido primero, es como el huevo y la gallina.. Supongo que si el capitalismo fundó lugares, es más funcional que la mujer esté en la casa, cuando le es más funcional al capitalismo que la mujer labure para que haya más pelea por los puestos de trabajo, pero seguimos agarradas a las labores del hogar... Entonces siempre es funcional, es parte de la sociedad occidental”. (Paula, 29 años, empleada administrativa).

Un tercer tipo de explicación fue el que hizo hincapié en las "políticas económicas" como causal de la desigualdad, en este caso, de orden económico (un caso). A diferencia del primer tipo de explicación, en el que se hizo mención al capitalismo, aquí se entendió que

\footnotetext{
${ }^{21}$ Hay un ejemplo muy claro sobre este posible problema recolectado en Balvé et al. (2005), aunque con relación al concepto de socialismo y no de capitalismo. Se trata de una entrevista que los autores hicieron a un militante sindical en el marco del "Cordobazo". El diálogo fue el siguiente: "P: Ahora, ¿qué entendería usted por socialismo? R: Bueno, mire... vea... este... yo, para mí, interpreto... mire a lo mejor no lo sepa explicar, no quisiera decirlo así porque a lo mejor yo me puedo equivocar. Lo que yo para mí interpreto, para mí está bien. Ahora yo, a lo mejor yo... a ver si tengo por acá cerca algún compañero que le puede dar mejor información..." (Balvé et al., 2005: 45).
} 
la causa de la desigualdad era de orden coyuntural y no debido al sistema socioproductivo dominante. En este sentido, en la perspectiva del entrevistado que expresó esta opinión, la implementación de unas u otras políticas económicas que amplían o reducen la desigualdad depende de quién gobierne el país en determinado momento histórico. Veamos el ejemplo:

"Desigualdad social siempre va a haber. Creo que siempre va a haber. Es imposible considerar una igualdad de condiciones al igual que el comunismo. Pero hay ciertas políticas económicas que generan mayor desigualdad, la acrecientan para un lado o para el otro. Siempre la clase más alta de todas es poca, pero hay que ver cuánto cúmulo de riqueza tiene y las clases bajas, y la clase media, media baja esa es la que se va distribuyendo entre más baja o subiendo un poco, pero esto no se mueve, claramente no se van a mover nunca, las clases media y baja, por ahi la baja puede llegar a subir un poco”. (Rubén, 29 años, vendedor).

Un cuarto tipo de explicación entendía que las desigualdades tenían origen en la "desigualdad de oportunidades" (un caso). En la perspectiva de la entrevistada que respondió de este modo, todas las personas tenían las mismas capacidades. Sin embargo, las oportunidades aparecían concentradas en pocas personas y esto daba lugar a la existencia de las desigualdades.

"Las diferencias están en las oportunidades al que uno está más abierto en su realidad. Quizás hay gente que tiene más posibilidades que otras. (...) Todos tenemos una base, después la vida te da una serie de oportunidades y facilidades que se pueden dar para que se haga un camino más fácil o más complejo para ese camino que quieras llevar". (Natalia, 33 años, ingeniera en alimentos).

Un quinto tipo de explicación colocaba el énfasis en la "concentración de poder" (un caso). En esta línea, quienes tenían "más poder" tenían "más oportunidades". Esta respuesta guarda una proximidad con la anterior. No obstante, el acento está puesto en la cuestión del poder. En tal sentido, se trata de una respuesta que contiene una complejidad de elementos mayores.

Veamos el ejemplo:

"No, creo que quien tiene más poder o más contactos tiene más oportunidad que otros. No sé qué porcentaje de personas en Argentina tienen acceso al poder. Creo que la minoría, sin embargo, tienen acceso a todo. Y son los que manejan el país. Acceso al poder económico, político, social". (Indira, 33 años, empleada administrativa).

Una última forma de explicar las desigualdades hacía referencia a la existencia de cierta "cultura" que avalaba un trato diferencial a las personas con determinados atributos particulares, "los pobres". En esta línea, en la mirada de la entrevistada que respondió de este modo, existía en algún sector de la población un conjunto de significaciones que habilitaban la discriminación de una determinada población, según ciertos rasgos.

Veamos el ejemplo: 


\begin{abstract}
“(...) porque la policía siente que tiene el poder y la autoridad para pegarle o meter preso a una persona solo por el hecho de ser pobre...porque la verdad que no sabes si cometieron un delito o algo. Es como un abuso de poder un poco...". (Camila, 29 años, empleada administrativa en empresa realizadora de comerciales).
\end{abstract}

Tal como señalamos más arriba, las respuestas recolectadas acerca de las explicaciones de las desigualdades eran heterogéneas al menos en dos sentidos: por un lado, fueron mencionadas varios factores como posibles causales de las desigualdades; por otro lado, dichas explicaciones eran diversas en cuanto a su grado de elaboración. En este último sentido, podemos sostener que había respuestas con mayor capacidad explicativa que otras.

Por otra parte, nos parece importante resaltar que en ningún caso se buscó explicar las desigualdades sociales de otro modo que no sea socialmente. Según lo que se desprende de las respuestas relevadas, ninguna esencia era interpretada como causal de alguna desigualdad social. En este sentido, las desigualdades sociales intentaron ser explicadas socialmente y no de otro modo, ya sea con base en cuestiones esencialistas o biologicistas, muy comunes en otros contextos históricos para explicar y justificar las desigualdades sociales entre las personas. En este caso, las respuestas se diferenciaron de las obtenidas sobre las explicaciones acerca de las divisiones sociales, en las que se observaron argumentos que atribuían las divisiones a la existencia de cierto "ser nacional".

Por último, indagamos acerca de si el Estado tenía, según la mirada de los asalariados entrevistados, algún tipo de responsabilidad en las desigualdades observadas en la Argentina contemporánea y cuáles eran estas. Las preguntas que realizamos en esta dirección fueron las siguientes: “¿Usted cree que el Estado tiene alguna responsabilidad en las diferencias que señaló? ¿Cuál o cuáles serían esas responsabilidades?”.

Con relación a la primera cuestión, observamos que la totalidad de nuestros entrevistados señaló que el Estado tenía alguna responsabilidad ante las desigualdades sociales que también según su perspectiva- existían en la Argentina.

Ahora bien, con respecto a la segunda cuestión, es decir, a los tipos de responsabilidades del Estado, registramos dos tipos de argumentos que hacían énfasis en diferentes cuestiones. En ambos casos se atribuía responsabilidad al Estado, sin embargo, esto se hacía desde ópticas distintas.

El primer argumento observado señalaba que el Estado era responsable de las desigualdades en tanto que generaba o garantizaba la existencia de estas. Este argumento era minoritario en términos cuantitativos (seis casos). Sobre el mismo, podría señalarse que guardaba -más claramente en algunos casos que en otros- cierta proximidad con la perspectiva marxista del Estado, en la que el Estado es interpretado como el instrumento de dominación de una clase social sobre otra. ${ }^{22}$

Veamos dos ejemplos de este tipo de argumento:

\footnotetext{
${ }^{22}$ Sobre este punto, Lenin, señaló: "La historia demuestra que el Estado, como aparato especial para la coerción de los hombres, surge donde y cuando aparece la división de la sociedad en clases, o sea, la división en grupos de personas, algunas de las cuales se hallan permanentemente en situación de apropiarse del trabajo ajeno, de explotar a otros. (...) El Estado es una máquina para asegurar la dominación de una clase sobre otra" (Lenin, 1971: 343-346).
} 
"Sí, porque el Estado es como una clase social. Vive para garantizar las intenciones y legalizar las intenciones de una clase. No existe un Estado neutral". (Sergio, 37 años, operario metalúrgico).

"Sí, completamente. Las políticas... veo mucha intervención del Estado. Se cerró "Conectar igualdad", se despiden trabajadores de la línea 144, se van cerrando un montón de cosas, se fomentan los despidos, entonces yo me quedo sin estudiar. (...) Esto es intervención estatal también, pero para pudrirla”. (Paula, 29 años, empleada administrativa).

El segundo tipo de argumento registrado afirmaba que la responsabilidad del Estado ante la desigualdad pasaba por no cumplir con ciertas tareas de intervención/contención que se esperaba que este llevara adelante. Este segundo tipo de argumento era en términos cuantitativos mayoritario (ocho casos), aunque no de forma abrumadora.

A diferencia del argumento anterior, en este se hacía hincapié en las funciones de contención social que -según esta visión- el Estado estaba obligado a realizar, pero que no cumplía. De ahí, su responsabilidad ante la desigualdad. De esta manera, dicho argumento se emparentaba con las perspectivas propias de los Estados de bienestar, en las que los Estados debían velar por una serie de derechos de su población (Gorz, 2003). Veamos dos ejemplos de este tipo de fundamentación:

"Cada vez aumenta la cantidad de gente que está en situación de calle. Creo que eso el Gobierno o el Estado tendría que hacer algo". (Elías, 26 años, técnico en ascensores).

"El Estado siempre va a ser responsable, pero porque está en la constitución. Si vos en la constitución velás por los derechos de cada uno de los ciudadanos a tener sanidad, un puesto de trabajo, una vivienda digna, bueno, tenés que velar por eso, cueste lo que cueste". (Rubén, 29 años, vendedor).

En suma, ya sea por una razón u otra, el Estado apareció en la mirada de nuestros entrevistados como un organismo responsable ante las desigualdades que percibidas. Pasemos ahora a dar cuenta de algunas conclusiones de lo analizado hasta aquí.

\section{Conclusiones}

En el presente trabajo, realizamos una aproximación exploratoria -con base en entrevistas- sobre las representaciones acerca de algunas cuestiones relativas a la unidad/división social y la igualdad/desigualdad social, en trabajadores asalariados del AMBA. A continuación, presentamos algunas conclusiones que surgieron a partir del análisis de los resultados obtenidos:

Una primera cuestión que observamos es que era ampliamente dominante la idea de que los argentinos se encontraban "divididos" en diversos grados. En este sentido, casi la totalidad de nuestros entrevistados se expresaron en estos términos, coherentemente desde nuestro marco teórico- con un orden social que promueve de manera constante las divisiones, como es el sistema capitalista. Asimismo, si bien no de modo abrumador, la 
mayoría de los entrevistados consideraron que la división que observaban entre los argentinos era significativa.

En segundo lugar, en la perspectiva de los asalariados, las divisiones que observaban se explicaban por varias razones. A excepción de un tipo de explicación que señaló ciertos rasgos del "ser nacional" como razón de las divisiones, la amplia mayoría de las respuestas tendió a explicar socialmente las divisiones sociales. No implica esto, no obstante, que la amplia mayoría de las respuestas explicaran la realidad de las divisiones sociales contemplando la complejidad de la cuestión. En esta línea, fueron muy pocos los entrevistados que intentaron explicar algunas de las divisiones sociales apelando al sistema socio-productivo dominante. Hubo en este sentido una cantidad importante de respuestas que plantearon que las divisiones obedecían a "estilos de vida" o a "visiones diferentes del mundo", sin buscar poner en relación dichas explicaciones con el orden social establecido.

Otra dimensión de las representaciones sobre las divisiones sociales que nos interesaba indagar era la relativa a la cuestión del origen temporal de las mismas. Consideramos que dicha aproximación nos permitiría conocer de mejor manera las representaciones sobre la división/unidad social. Sobre este punto, observamos que algunos trabajadores tendieron a ubicar el origen de las divisiones sociales en el corto plazo, mientras que otros, con una perspectiva de largo plazo, sostuvieron que las mismas no eran recientes, contrariando el discurso de la "grieta", que ubicaba el inicio de las divisiones entre los argentinos en los gobiernos kirchneristas. Cuantitativamente, estos últimos fueron amplia mayoría. En lo que respecta al futuro de las divisiones observadas, la amplia mayoría de los entrevistados consideraron que las mismas se sostendrían en el tiempo. Fueron, en este sentido, mayoría quienes designamos en este plano como "pesimistas" con relación a la unidad de los argentinos.

Una segunda parte de nuestro trabajo se enfocó en una cuestión próxima pero diferente a la de las divisiones: la igualdad/desigualdad social.

Sobre este punto, registramos que la totalidad de los asalariados entrevistados consideraron que existían desigualdades entre los argentinos. Asimismo, su perspectiva, las desigualdades se daban en una diversidad importante de ámbitos en la Argentina contemporánea. Entre esa diversidad temática, las desigualdades de tipo económicas fueron las más mencionadas.

En cuanto a las formas de explicar las mismas, nos encontramos con una diversidad significativa. Las mismas refirieron al sistema capitalista aunque también a cuestiones de tipo coyuntural, siendo mayoría las de este último tipo. No obstante ello, tal como advertimos más arriba, no puede descontarse que la referencia al capitalismo signifique un pleno conocimiento del funcionamiento de dicho sistema económico-social. Notamos, al mismo tiempo, que las explicaciones sobre las desigualdades contenían una heterogénea elaboración, siendo algunas explicaciones más complejas y otras más simples.

Por último, observamos que los entrevistados consideraron en su totalidad que el Estado tenía responsabilidad en relación con las desigualdades existentes en el país. Estas eran de dos tipos diferentes: por un lado, en la medida que comprendían que el Estado generaba o garantizaba las mismas, por el otro, porque no cumplía con ciertas tareas de cuidado que éste debía cumplir, en tanto agente de contención. 
En suma, el análisis de las representaciones sobre ambas cuestiones, las divisiones y las desigualdades sociales, en trabajadores asalariados del AMBA, nos permitió avanzar en el conocimiento acerca de los modos en que se interpretaban dimensiones diversas de dichas temáticas; a partir de lo cual, observamos que la compresión compleja del orden social es algo que por el momento es minoritaria al menos en la personificación social que exploramos.

\section{Bibliografía}

-Artese, M., Castro Rubel, J. y Tapia, H. (2017). Experiencias políticas y representaciones sobre el conflicto y la cohesión social en asalariados del Área Metropolitana de Buenos Aires. Espacio Abierto, vol. 26, $\mathrm{n}^{\circ}$ 3, (5-24). Recuperado de file://C:/Users/Jorge/Downloads/Dialnet-

CronologiaHistoricaDeLasPoliticasDeViviendaParaLos-6116885.pdf.

-Balvé, B., Murmis, M., Marín, J. C., Aufgang, L., Bar, T., Balvé, B. y Jacoby, R. (2005). Lucha de calles, lucha de clases. Elementos para su análisis (Córdoba 1971-1969). Buenos Aires: Ediciones R y R.

-Castro Rubel, J., Artese, M. y Tapia, H. (2018). Las nociones sobre la división y el conflicto social en los trabajadores asalariados del Área Metropolitana de Buenos Aires (AMBA). Revista Kairós, temas sociales, $\mathrm{n}^{\circ}$ 41, (1-22). Recuperado de http://www.revistakairos.org/las-nociones-sobre-la-division-y-el-conflicto-social-enlos-trabajadores-asalariados-del-area-metropolitana-de-buenos-aires-amba/.

-Cotarelo, M. C. (2018). Desarrollo de una fuerza social del régimen de carácter oligárquico. Los cacerolazos de 2012 en Argentina. Revista Theomai, № 37 (173-187). Recuperado de http://revista-theomai.unq.edu.ar/NUMERO 37/9. Cotarelo 37.pdf. -Coser, L. (1961). Las funciones del conflicto social. Buenos Aires: Fondo de Cultura Económica.

-Durkheim, E. (1997). La división del trabajo social. México: Colofón.

-Eagleton, T. (2017). Cultura. Buenos Aires: Taurus.

-Elías, N. (1990). La sociedad de los individuos. Barcelona: Península.

-Fernández Díaz, J. (16 de abril de 2018). José Nun: "Si les subieran los impuestos a las fortunas personales, no haría falta el endeudamiento". La Nación. Recuperado de https://www.lanacion.com.ar/2125920-jose-nun-si-les-subieran-los-impuestos-a-las-

fortunas-personales-no-haria-falta-el-endeudamiento

-Gorz, A. (2003). Miserias del presente, riquezas de lo posible. Paidós: Buenos Aires.

-Lenin, V. (1971). Obras completas. Editorial Cartago: Buenos Aires.

-Marx, K. (1976). El capital. Crítica de la economía politica. Madrid: Akal.

-Marx, K. y Engels, F. (2017). Manifiesto del Partido Comunista. Buenos Aires: Siglo XXI.

-Nisbet, R. (1969). La formación del pensamiento sociológico. Buenos Aires: Amorrortu. -Nun, J. (8 de septiembre de 2011). ¿Y si el problema son los ricos? La Nación. Recuperado de https://www.lanacion.com.ar/1404256-y-si-el-problema-son-los-ricos

-Raiter, A. (2010). Representaciones sociales. Recuperado de http://iigg.sociales.uba.ar/wp-content/uploads/sites/49/2011/03/dcdi.pdf.

-Romero, J. L. (2013). Breve historia de la Argentina. Buenos Aires: Fondo de Cultura Económica. 
-Rosanvallon, P. (2015). La sociedad de iguales. Buenos Aires: Manantial.

-Tapia, H., Castro Rubel, J y Artese, M. (Diciembre, 2017). Límites y profundidades de "La grieta". Una exploración sobre las nociones de división y cohesión social en trabajadores asalariados del AMBA. En XXXI Congreso de la Asociación Latinoamericana de Sociología, Universidad Nacional de la República, Montevideo, Uruguay.

-Therborn, G. (2015). Los campos de exterminio de la desigualdad. Buenos Aires: Fondo de Cultura Económica.

-Tilly, Ch. (2000). La desigualdad persistente. Buenos Aires: Manantial.

-Thompson, E. P. (2012). La formación de la clase obrera en Inglaterra. Madrid: Capitán

Swing.

-Walsh, R. (5 de septiembre de 2018). Cordobazo. Semanario CGT. Recuperado de http://cgtargentinos.org/documentos6.htm.

-Weber, M. (2002). Economía y Sociedad. Madrid: Fondo de Cultura Económica.

-Zunino, E. y Russo, C. (2015). Cerrar la grieta. Ideas urgentes para el reencuentro de los argentinos. Buenos Aires: Sudamericana. 